\title{
Kennisagenda samen gezond leven: hoe dan?
}

\author{
Luc Hagenaars $(\mathbb{D} \cdot$ Fleur Boulogne · Hans van Oers · Caroline Baan · Henk Garretsen
}

Geaccepteerd op: 24 november 2021 / Published online: 23 december 2021

(C) The Author(s) 2021

Samenvatting In het begin van 2020 heeft staatssecretaris Paul Blokhuis het Kennisplatform Preventie in het leven geroepen. Dit platform bestaat uit experts uit de wetenschap, het beleid en de praktijk van preventie. Het doel is om tot meer samenhang te komen in de programmering en het gebruik van kennis over preventie, aan de hand van een dynamische kennisagenda. In haar meest recente agenda (Kennisagenda preventie 2021: mentale gezondheid op de agenda - ZonMw) stelt het kennisplatform dat hoevragen meer prioriteit verdienen dan wat-vragen, als het gaat om leefstijl en mentale gezondheid. Dit artikel licht de aanleiding en inhoud van de kennisagenda en het kennisplatform toe, en roept lezers op om mee te denken via kennisplatformpreventie@zonmw.nl.

\section{Research agenda living healthy together, but how?}

Abstract At the beginning of 2020, Secretary of State Paul Blokhuis introduced the Knowledge Platform Prevention. This platform consists of scientific, practice-based and policy experts in the field of prevention. The objective of the platform is to improve the cohesion and usage of knowledge about prevention, with a dynamic research agenda. The most recent agenda (Kennisagenda preventie 2021: mentale gezondheid op de agenda-ZonMw)

\section{Dr. L. Hagenaars $(\bowtie)$}

Amsterdam UMC, Amsterdam, Nederland

kennisplatformpreventie@zonmw.nl

F. Boulogne, MPhil

Ministerie van Volksgezondheid, Welzijn en Sport,

Den Haag, Nederland

Prof. dr. H. van Oers · Prof.dr. C. Baan .

Em. prof.dr. H. Garretsen

Tranzo, Tilburg University, Tilburg, Nederland itemizes that how-questions should be prioritized above what-questions in the field of (mental) health promotion. This paper describes how this platform came about as well as the content of its research agenda. It also asks readers to think along how the agenda can be implemented or improved, by reaching out to kennisplatformpreventie@ zonmw.nl.

\section{Inleiding}

De wetenschap, het beleid en de praktijk worden vaak als op zichzelf staande werelden gezien. Ook in de publieke gezondheid bestaat dit beeld. Wetenschappers zoeken vanuit dit perspectief onder andere naar verbanden tussen oorzaak en gevolg met gegevens uit het verleden. Beleidsmakers proberen de toekomst een stukje te verbeteren door al dan niet werkbare oplossingen te bedenken. En in de praktijk wordt in de rauwe werkelijkheid van het hier en nu concreet aan een betere volksgezondheid gewerkt.

Echte wijsheid ontstaat wanneer de kennis en ervaringen uit de wetenschap, het beleid en de praktijk van alledag elkaar ontmoeten [1]. Daarom is op initiatief van het Ministerie van VWS in januari 2020 een zogenaamd Kennisplatform Preventie in het leven geroepen. Dit platform bestaat uit wetenschappers, beleidsmakers en uitvoerders van preventie en heeft tot doel om te komen tot meer samenhang in de programmering en het gebruik van kennis over preventie. Naar aanleiding van de eerste kennisagenda van juni 2020 en de update van de kennisagenda die in juli 2021 is opgeleverd, zetten we in dit artikel de aanleiding en inhoud van de kennisagenda uiteen. We sluiten af met een blik op de toekomst en een uitnodiging om de in de agenda beschreven verbeterpunten tot wasdom te laten komen. 


\section{Aanleiding: kennisprogrammering van preventie kan beter}

Eind 2019 constateerde het Ministerie van VWS dat er veel kennisontwikkeling op het gebied van preventie plaatsvindt, maar dat er sprake is van fragmentatie in het onderzoek zelf, de programmering en het gebruik van die kennis. Dit terwijl er het nodige te doen is: de ambities uit het Preventie- en Sportakkoord en de te verwachten realisatie daarvan komen niet overeen. Dat komt onder andere door een kennishiaat over effectieve maatregelen en de toepassing daarvan [2].

Om meer te sturen op de vraag waar onderzoek zich op moet richten, en welke prioriteiten hierbij moeten worden gesteld, bracht staatssecretaris van VWS Paul Blokhuis in januari 2020 een werkgroep bijeen: het Kennisplatform Preventie. Dit kreeg als opdracht een dynamische kennisagenda te ontwikkelen, die kan helpen bij het verbeteren van de kennisprogrammering, in eerste instantie ten aanzien van roken, overgewicht, problematisch alcoholgebruik en bewegen (de thema's uit de preventie- en sportakkoorden). De agenda wordt periodiek geüpdatet om relevant te blijven. Leden van het platform nemen deel op persoonlijke titel en op basis van hun ervaring in de wetenschap, beleidsvorming en praktijk (zie bijlage 1 van de kennisagenda 2021 voor de samenstelling van het platform) [3]. Het kennisplatform is onafhankelijk en heeft ook een onafhankelijke voorzitter in de persoon van prof.dr. Henk Garretsen (Tilburg University). ZonMw voert het secretariaat, in samenwerking met het ministerie van VWS. Beleidsmakers op het ministerie vormen ook een belangrijke doelgroep van de agenda, maar in feite is het de bedoeling dat de agenda zo veel mogelijk mensen bereikt die met de ontwikkeling en benutting van kennis over preventie bezig zijn.

Om de discussie tussen de platformleden te voeden en structureren, vroeg het secretariaat van het platform in het voorjaar van 2020 Pluut \& Partners een documentenanalyse en Delphi-onderzoek uit te voeren [4]. De preventie- en sportakkoorden en de kennisagenda preventie die in het kader van de Nationale Wetenschapsagenda is opgesteld, dienden hierbij als basis. Pluut \& Partners analyseerden tientallen overzichtsonderzoeken en kennisagenda's over deelgebieden (bijvoorbeeld sport en bewegen), en consulteerden via twee Delphi-rondes achtereenvolgens 81 en 78 experts, met een responsratio van respectievelijk $69 \%$ en $53 \%$. Van de geconsulteerde experts was $36 \%$ primair actief binnen de wetenschap, $35 \%$ voornamelijk in het beleid en $24 \%$ vooral in de praktijk.

\section{Kennisagenda Samen Gezond Leven 1.0}

In de exercitie van Pluut \& Partners benadrukten experts dat kennisontwikkeling zich vooral moet richten op hoe-vragen. De teneur is dat we in algemene zin goed weten wat werkt om gezond gedrag te bevorde- ren. Zo bevat de database van het Loket Gezond Leven 75 interventies met eerste, goede of sterke aanwijzingen voor effectiviteit en is er via collectieve preventie in de leefomgeving en het beprijzen van ongezonde voeding en alcohol tegen beperkte kosten nog veel gezondheidswinst te behalen [5, 6]. Maar we weten nog onvoldoende hoe we breder kunnen implementeren wat volgens theorie, empirie en pilots werkt. Dit hiaat doet zich op politiek niveau voor, bijvoorbeeld bij de vraag waarom de politiek bewezen kosteneffectieve maatregelen als een belasting op ongezonde voeding nog niet heeft ingevoerd. Het speelt ook op het niveau van bestuur, organisatie en uitvoering van preventie. Bijvoorbeeld bij de vraag waarom het tien jaar duurde voordat de Gecombineerde Leefstijl Interventie (GLI) in de praktijk werd aangeboden, na de bepaling van het College voor Zorgverzekeringen in 2009 dat er genoeg bewijs is om een GLI onderdeel te maken van het verzekerde pakket [7]. En het speelt op individueel niveau: weten is nog geen doen. De vraag is hoe we beter kunnen inspelen op het doenvermogen van mensen, omdat zij vaak wel weten welk gedrag gezond is, maar daar niet naar handelen [8].

De noodzaak om meer hoe-vragen te onderzoeken werd na het Delphi-onderzoek in vier focuspunten opgedeeld. Ten eerste vonden experts het gewenst om de randvoorwaarden voor opschaling van effectieve maatregelen te onderzoeken. Het gaat dan bijvoorbeeld om kennisvragen als wie bij nieuwe maatregelen welke verantwoordelijkheden heeft, en wie daarvoor de kosten moet dragen. Ten tweede achtte men het noodzakelijk om implementatiebelemmeringen beter te begrijpen, bijvoorbeeld als het gaat om het ontbreken van kennis over of middelen voor preventie, of problemen in de toeleiding van die kennis of middelen naar de plek waar een preventiemaatregel kan worden uitgevoerd. Een derde leidende focus is dat inzet op preventie integraal moet zijn. Integraal beleid maken en zeker uitvoeren is echter notoir moeilijk doordat beleid in beginsel in verschillende sectoren is opgedeeld. Kennisvragen hierbij betreffen bijvoorbeeld (politieke) agendering in sectoren waar gezondheid niet het primaire doel is, maar waarvan het beleid wel invloed heeft op de gezondheid. Ten slotte achtten experts het noodzakelijk dat maatregelen met de doelgroep samen worden ontwikkeld. Relevante kennisvragen gaan bijvoorbeeld over de methodiek van dergelijk participatief onderzoek, en de manier waarop de huidige onderzoekinfrastructuur kan worden aangepast om dit soort onderzoek te stimuleren. Het kennisplatform vertaalde de bevindingen van Pluut \& Partners naar zeven aanbevelingen in de eerste kennisagenda van juni 2020 (zie kader 1).

\section{Kennisagenda Samen Gezond Leven 2.0}

Eind 2020 werd deze eerste versie van de kennisagenda Samen Gezond Leven geëvalueerd door het kennisplatform zelf, onder andere op basis van in het 
najaar 2020 gevoerde gesprekken met beleidsmakers van VWS. De aanbevelingen bleken herkenbaar en worden deels al uitgevoerd. Zo is de ZonMw-ronde Gemeenten Samen Gezond gebaseerd op de kennisagenda met zes thema's die aansluiten bij de aanbevelingen over governance, financiering, monitoring en evaluatie en cocreatie voor de doelgroep [9]. Ook zijn er in 2020 in opdracht van VWS diverse onderzoeken gedaan naar de huidige uitgaven aan en financieringsmogelijkheden van gezondheidsbevordering, om meer greep te krijgen op de financiering van gezondheidsbevordering als implementatiebelemmering [10, 11 .

De conclusie was ook dat de aanbevelingen wel wat concreter konden. Daarom zijn in de update van de agenda, die in juli 2021 uitkwam, voorbeelden opgenomen van onderzoek of onderzoeksplannen die goed beschrijven welk type onderzoek aansluit bij aanbevelingen 4 en 6 , monitoring en evaluatie, en cocreatie met de doelgroep. Er is op pragmatische gronden gekozen om deze twee aanbevelingen op te pakken [3].

Enkele platformleden hebben samen twee notities opgesteld voor deze twee aanbevelingen (bijlagen IV en $\mathrm{V}$ in de kennisagenda 2021). Ten aanzien van monitoring en evaluatie is verduidelijkt dat kort cyclisch leren bij een integrale aanpak kwantitatief onderzoek vergt. Maar narratieve verantwoording is evengoed belangrijk en sluit ook beter aan bij de complexiteit van een integrale aanpak. Het devies is dus om te tellen én te vertellen.

Ten aanzien van cocreatie met de doelgroep concludeerden platformleden dat vertrouwen het sleutelwoord is. Vertrouwen in het proces van cocreatie, vertrouwen in de participerende burgers door professionals en vertrouwen van burgers in de professionals. Vertrouwen komt te voet en gaat te paard, en dus is er een significante tijdsinvestering nodig. Bij kortlopende projectvormen is die tijd er niet altijd. Ook staat bij succesvolle cocreatie het proces centraal in plaats van de uitkomst. Daar past sturen op procesindicatoren bij, in aanvulling op de reguliere sturing op basis van uitkomstindicatoren.

Deze twee specificaties laten zien hoezeer de aanbevelingen met elkaar verband houden. Kennis over wat financiers nodig hebben voor contracteren en verantwoording kan bijgestuurd worden door innovaties in monitoring en evaluatie die meer recht doen aan de complexiteit van een integrale aanpak. Cocreatieprocessen vergen andere kennis over governance, en zo zijn er nog meer dwarsverbanden te leggen. Een cruciale vraag voor lezers van het TSG is hoe de kennisinfrastructuur kan bijdragen aan het uitwerken van deze dwarsverbanden. Wij zien drie spanningen omtrent deze aanbeveling 3, alle beginnend met een hoofdletter V. Allereerst stelt het platform dat de kennisontwikkeling en kennisdeling te Versnipperd is - het is de vraag hoe meer Verbindingen kunnen worden gelegd. Ten tweede is er de spanning in welke mate kennisontwikkeling en kennisdeling een Vrijblijvend dan wel Verplichtend karakter moeten hebben. Ten derde is het platform het erover eens dat Versterking van kennisinfrastructuur nodig is. Maar hoe organiseer je dat als zoveel meer onderwerpen om Voorrang op de beleidsagenda strijden? Voor deze spanningen heeft het kennisplatform geen panklare oplossing en is inbreng van TSG-lezers gewenst.

Naast specificatie van de bestaande agenda was er binnen het kennisplatform de behoefte om het thema mentale gezondheid aan de agenda toe te voegen, in lijn met een recente Kamermotie over een nationaal preventieakkoord mentale gezondheid [12]. Pluut \& Partners heeft ook voor deze behoefte een Delphi-onderzoek uitgevoerd [13]. Uit de verkenning bleek dat het begrippenkader van mentale gezondheid minder helder is, vergeleken met de bekende leefstijlfactoren alcohol, bewegen, overgewicht en roken. Experts vonden dit belangrijk, want zonder begripsconsensus is het lastig om tot overeenstemming te komen over probleemanalyse en gewenste oplossingsrichtingen. Ook vond men het belangrijk om beter te begrijpen wat de onderliggende individuele, sociale en maatschappelijke determinanten van mentale gezondheid zijn.

Tegelijkertijd was het platform van mening dat de aanbevelingen van de eerste kennisagenda Samen Gezond Leven, die zich exclusief richtte op gezonde leefstijl, grotendeels ook van toepassing zijn op mentale gezondheid. Ook bij mentale gezondheid verdienen implementatievraagstukken prioriteit en acht men het nodig om beter te begrijpen hoe een integrale aanpak gerealiseerd kan worden, rekening houdend met contextuele verschillen in bijvoorbeeld demografie, epidemiologie, cultuur, zorglandschap en politiek-bestuurlijke verhoudingen. Naast wat-vragen, spelen er ook bij mentale gezondheid dus vooral hoe-vragen. Dat heeft geleid tot aanvullingen op de aanbevelingen uit de eerste kennisagenda (cursief in kader 1).

\section{Gebruik en doorontwikkeling van de kennisagenda}

Terugblikkend op anderhalf jaar Kennisplatform Preventie, valt ons op dat er veel commitment aanwezig is bij de platformleden. Daar zijn wij de leden zeer erkentelijk voor, gezien hun drukke agenda's en de impact van de coronacrisis. Tegelijkertijd zien we dat de kennisagenda nog aan bekendheid kan winnen en dat het daadwerkelijk toepassen ervan voor kennisprogrammering binnen VWS en daarbuiten nog beter kan. Ook hier speelt de hoe-vraag dus kennelijk een rol. Dat is ook een reden voor het schrijven van dit artikel. Wij roepen lezers op om mee te denken bij het implementeren en doorontwikkelen van de agenda, zeker waar het gaat om de kennisinfrastructuur (aanbeveling 3). Daarom zijn we benieuwd hoe deze aanbevelingen betrekking hebben op het werk van lezers, en nodigen we eenieder uit om via het secretariaat van het kennisplatform bij ZonMw, kennisplatform- 
Kader 1 Aanbevelingen uit de kennisagenda samen gezond leven 2020. Aanvullingen na actualisatie in 2021 in cursief. Bron: https://publicaties.zonmw.nl/kennisagenda-preventie/. De aanvullingen op de aanbevelingen uit de eerste kennisagenda zijn cursief gezet

1. Governance. Versterk kennis onder andere over het beleidsproces van effectieve maatregelen en randvoorwaarden voor lokale/regionale preventie-infrastructuren en intersectoraal beleid.

Stimuleer kennisontwikkeling en -gebruik over werkzame elementen en succesfactoren bij de integrale aanpak van mentale gezondheidsproblemen. Dit vergt kennis over de contextgevoelige implementatie van specifieke vormen van (secundaire) preventie, en kennis over intersectorale samenwerking, vooral waar het gaat om het snijvlak van het sociaal domein, de publieke gezondheid en de zorg.

2. Financiering. Versterk kennis over onder andere de kosten en baten van preventie en innovatieve bekostigingsmodellen.

3. Borging van kennis(infrastructuur). Stimuleer kennisdeling tussen communities of knowledge (tussen regio's, thema's, sectoren en/of goede praktijken).

Bevorder het overzicht van kennis over succesvolle vormen van preventie van mentale en fysieke gezondheidsproblemen.

4. Monitoring en evaluatie. Bevorder het kortcyclisch leren bij een integrale aanpak en de methodologische innovatie die daarvoor nodig is.

Bevorder een participatieve evaluatiewijze die rekening houdt met de complexiteit van een integrale aanpak, waarbinnen zowel recht wordt gedaan aan een narratieve verantwoording als aan een verantwoording op basis van kwantitatieve gegevens.

5. Leefomgeving. Breng kennis samen en bevorder nieuwe kennisontwikkeling over een gezonde leefomgeving.

6. Cocreatie met de doelgroep. Stimuleer kennisontwikkeling over en -benutting van de perspectieven van burgers met het grootste gezondheidspotentieel.

7. Gebruik van data en online toepassingen. Stimuleer kennisontwikkeling over en -benutting van online toepassingen op zo'n manier dat deze aansluiten bij burgers met het grootste gezondheidspotentieel.

8. Mentale gezondheid. Stimuleer kennisontwikkeling over en -gebruik van beïnvloedbare risicofactoren van mentale gezondheidsproblemen en de interactie met fysieke gezondheidsproblemen.

Stimuleer kennisontwikkeling over en -gebruik van effectieve sociale inclusie, bijvoorbeeld door destigmatisering.

preventie@zonmw.nl, contact op te nemen. Inbreng is waardevol omdat de platformleden zich momenteel beraden op de toekomst van de agenda. Die ligt nog niet vast, maar er is dus vooral behoefte om aanbevelingen toe te passen en te concretiseren, in plaats van nieuwe aanbevelingen te formuleren.

Deze richting past ook bij onze constatering dat de aanbevelingen over het algemeen herkend worden, en de consensus die we in de publieke gezondheid opmerken dat er een groter kennishiaat bestaat ten aanzien van hoe-vragen, dan wat betreft wat-vragen. Dit geldt voor mentale gezondheid en zeker voor gezonde leefstijl. Hetzelfde lijkt ook in de zorg het geval. Zo zijn de hoe-vragen ook een belangrijke focus van de aanbevelingen van de kennisagenda Juiste Zorg op de Juiste Plek [14]. Tegelijkertijd is niet altijd bekend dat implementatievraagstukken gebaat kunnen zijn bij wetenschappelijk onderzoek, zijn wetenschappers niet altijd in staat om dergelijk onderzoek uit te voeren en kan het voor beleidsmakers lastig zijn om op dit vlak heldere kennisvragen te formuleren.

De onderbenutting van kennis in het beleid en de uitvoering speelt breder, zo constateerde de Adviesraad voor Wetenschap, Technologie en Innovatie (AWTI) onlangs in het advies 'Rijk aan kennis' [15].
De AWTI stelt dat een betere kennisinbedding nodig is in beleidsprocessen en dat daarvoor een bredere kennisbasis nodig is binnen de departementen, de uitvoeringsorganisaties en de Tweede Kamer. Dit is relevant om te anticiperen op toekomstige crises en voor de aanpak van grote maatschappelijke uitdagingen.

Kortom, de weg naar wijsheid vergt een stevigere kennisinfrastructuur die de continue vertalingsslag en interactie tussen kennis, beleid en praktijk kan stimuleren. Dit geldt zeker voor de maatschappelijke uitdagingen op het vlak van gezond gedrag en mentale gezondheid. Samen gezond leren leven doe je dus ook beter niet alleen.

Open Access This article is licensed under a Creative Commons Attribution 4.0 International License, which permits use, sharing, adaptation, distribution and reproduction in any medium or format, as long as you give appropriate credit to the original author(s) and the source, provide a link to the Creative Commons licence, and indicate if changes were made. The images or other third party material in this article are included in the article's Creative Commons licence, unless indicated otherwise in a credit line to the material. If material is not included in the article's Creative Commons licence and your intended use is not permitted by statutory regulation or 
exceeds the permitted use, you will need to obtain permission directly from the copyright holder. To view a copy of this licence, visit http://creativecommons.org/licenses/by/4.0/.

\section{Literatuur}

1. Verschuuren M, Oers H van. Population health monitoring. Climbing the information pyramid. Cham: Springer; 2019.

2. Rijksinstituut voor Volksgezondheid en Milieu. Quickscan mogelijke impact Nationaal Preventieakkoord. Bilthoven: RIVM;2018.

3. Kennisplatform Preventie. Kennisagenda preventie. Samen gezond leven 2020 en 2021. Den Haag: ZonMw; 2021.

4. Pluut \& Partners. Bouwstenen voor de kennisagenda preventie. Den Haag: Pluut \& Partners; 2020.

5. Rijksinstituut voor Volksgezondheid en Milieu. Loket Gezond Leven. Bilthoven: RIVM. 2021. https://www. loketgezondleven.nl/leefstijlinterventies/interventieszoeken-algemeen. Geraadpleegd op: 8 sep 2021.

6. Van Gils P, Suijkerbuijk A, Polder J, et al. Ook buiten preventieakkoord is veel gezondheidswinst te behalen tegen beperkte kosten. ESB Economisch Statistische Berichten. 2019. https://pure.uvt.nl/ws/portalfiles/portal/ 30929591/20_6_2019_Gils_P._F._V..pdf. Geraadpleegd op: 8 sep 2021.

7. Bekker MPM, Wagemakers MAE. Samenwerking organiseren voor preventie. Leren van de beleidsvorming voor de Gecombineerde Leefstijl Interventie. Wageningen: Wageningen University \& Research; 2021.
8. WetenschappelijkeRaadvoorhet Regeringsbeleid. Weten is noggeen doen. Een realistisch perspectiefop redzaamheid. Den Haag: WRR; 2017.

9. ZonMw. Subsidieoproep Gemeenten Samen Gezond. Den Haag: ZonMw. 2021. https://www.zonmw.nl/ $\mathrm{nl} /$ actueel/nieuws/detail/item/kennisagenda-preventie2021-mentale-gezondheid-op-de-agenda/. Geraadpleegd op: 27 sep 2021.

10. Rijksinstituut voor Volksgezondheid en Milieu. Landelijke en lokale uitgaven aan gezondheidsbevordering: een nulmeting. Bilthoven: RIVM;2021.

11. Broek T van den, Eerden S van, Veldhuisen A van. Hoe financieren we preventie met het oog op gezondheidsbevordering? Een onderzoek naar de best passende financieringswijze. Utrecht: Andersson Elffers Felix; 2021.

12. Tweede Kamer. Motie van de leden Dik-Faber en Diertens over een nationaal preventieakkoord mentale gezondheid. Den Haag: Tweede Kamer. 2021. https://www. tweedekamer.nl $/$ kamerstukken $/$ detail?id=2021Z02062\& did=2021D04467. Geraadpleegd op: 23 jul 2021.

13. Pluut \& Partners. Bouwstenen voor de kennisagenda preventie van mentale gezondheidsproblemen. Den Haag: Pluut\& Partners; 2021.

14. Kennisplatform De Juiste Zorg op de Juiste Plek. Kennisagenda 'Zorg op de Juiste Plek' 2020. Den Haag: ZonMw; 2020.

15. Adviesraad voor wetenschap, technologie en innovatie. Rijk aan Kennis. Naar een herwaardering van kennis en expertise in beleid en politiek. Den Haag: AWTI; 2021. 